Laboratorio de Arte,4-1991 http://dx.doi.org/10.12795/LA.1991.i04.15

\title{
EL COMERCIO DE OBJETOS ARTÍSTICOS ENTRE SEVILLA Y AMÉRICA (1927-1928)
}

\author{
por María José del Castillo Utrilla
}

Las exportaciones de obras artísticas y artesanales a América se concentran en los años inmediatamente anteriores a la Exposición Ibero-Americana de 1929 en los Estados del Sur de USA y en los más prestigiosos mercados del N.E. del país.

Las mercancías más frecuentes tenían una función decorativa, y no eran de un alto valor artístico, pero es interesante el comprobar el gusto por lo español que, a través de la documentación de Aduanas que incluimos, se centra alrededor de objetos domésticos y artesanales.

The export of works of art and craftwork to America in the years immediately prior to the IberoAmerican Exhibition of 1929, was concentrated on the Southern states of the U.S.A and the most famous markets of the North East.

Most of the merchandise was decorative, and of no great artistic value, but it is interesting to observe the taste for things Spanish as revealed by the Customs documents included here, which mainly deal with domestic objects and handcrafts.

El cnvío desde Sevilla a América de obras de arte y objetos artísticos en general supone una constante a lo largo de la Historia.

Desde los tiempos de la Conquista, y durante el período Virreynal, los centros religiosos y civiles más importantes se surtían de objetos españoles, y los artistas más acreditados enviaban sus producciones al Nuevo Mundo, cuando no eran ellos mismos los que se desplazaban para realizar su labor "in situ", como fue el caso de un Jerónimo Balbás, un Angelino de Medoro, o un Alonso de Narváez, entre otros muchos de diferentes categorías y estilos. 
Las obras exportadas pertenecieron en una buena parte a figuras de primera fila, sobre todo aquellas que tenían un destino religiosos, así vemos representados en diferentes países Hispano-Americanos a Juan Martínez Montañés, a Juan de Mesa y a Alonso Cano.

Pero no siempre las obras que se llevaban a América eran auténticas maravillas artísticas. En las relaciones de ajuares encontramos piezas de todo tipo, de carácter mobiliar y ornamental, sin mayores pretensiones.

Estos embarques, tan frecuentes durante el Virreynato, dependían de particulares e iban a engrosar el patrimonio de las familias establecidas en el Nuevo Continente. Es posible que en ocasiones también se enviaran algunos objetos con fines comerciales, no descartamos esa posibilidad '.

Esta costumbre de exportación de objetos artísticos desde España, y muy concretamente desde Sevilla, parece que se vio interrumpida durante el período de la Independencia, pero muy pronto, desde los finales del S. XIX, otra vez el Arte y la Artesanía españoles aparecen en América.

Las Exposiciones de pintura española en Argentina, por ejemplo, se hacen constantes durante los primeros veinte años del S. XX, y el gusto por lo andaluz, según las crónicas referentes a la Sala Castillo y a la Sala Witcomb, en Buenos Aires, ponen de manifiesto esta tendencia ${ }^{2}$.

Pero aquí no vamos a tratar del gran comercio de obras artísticas, ni de las obras de encargo, sino sencillamente de un aspecto más modesto, pero muy interesante, que es el del Comercio de Antigüedades, centrándonos, para acotar un tanto el amplísimo panorama que este aspecto nos plantea, en las exportaciones que los anticuarios de Sevilla hacen a América, en un período tan significativo como es el inmediatamente anterior a la Exposición Ibero-Americana de 1929.

Por eso, para centrar los datos, trataremos solamente de los envíos que se hacen entre 1927 y 1928.

Por la Aduana de Sevilla, y procedentes de casas de antiguiedades sevillanas, salieron para compañías americanas un número considerable de objetos, en su mayoría artesanales. El total de piezas que hemos contabilizado fue el de 291, de categoría y precios muy diversos, ya que oscilaron entre las 1.850 pesetas de un

1. Un estudio acerca del comercio de obras de Arte entre España y la América Virreinal lo realizó el Dr. D. PEDRO GONZÁLEZ GARCÍA en su Tesis de Licenciatura (inédita), defendida el año 1982 y titulada: El comercio de obras de Arte entre Sevilla e Hispano América a fines del S. XVI (1550-1600). Reseñamos éste por ser el último que conocemos acerca del tema.

2. Véase la Revista "La Ilustración Artística" (años 1902-1920), en la que el crítico D. Justo Solana, refiriéndose al gusto por lo español, dice, en referencia a la exposición organizada por el "marchand" D. José Pinelo, en el Salón Castillo de Buenos Aires: "El Arte español en general, y en particular la escuela sevillana, están de enhorabuena con la aceptación franca y entusiasta que tienen sus obras en lä populosa Buenos Aires...". 
bargueño mudéjar que envió Don Celestino Dupont a New York, en 1927 (fig. 1), hasta dos calderillos de cobre que fueron valorados en cuatro pesetas, y que entre otras muchas piezas fueron enviadas a Pasadena en el Estado de California por Don Manuel Adarve.

Entre tantos objetos como se enviaron también se incluían algunas obras de arte apreciables, como fue una imagen de la Virgen con Niño (S. XVI c.), que casualmente fue el único envío que tenía como destino un país sudamericano en esta época. Concretamente se trata de una talla de madera, de una buena factura, que Don José Pomés mandó a Buenos Aires a la consigna de Don Gregorio Centurión.

Esta obra, con ser aparentemente de buena calidad (fig. 2), no llegó a alcanzar una cotización alta, pues sólo se valoró en cuatrocientas cuarenta pesetas.

Dentro del mismo terreno de la escultura hay piezas importantes, como también lo es una Inmaculada, que por sus características nos parece del S. XVII, y que responde a la escuela granadina. Esta imagen, tallada en madera y policromada, fue exportada por Don Manuel Adarve a New York en marzo de 1928 a la consigna de Mr. Albert E. Stratton, junto con otros veinte objetos, entre los cuales, además de la citada Inmaculada (fig. 3), se encontraban otras tallas de Santos, cerámicas, piezas de hierro y de cobre, así como distintos muebles, que supusieron la mayoría del embarque.

En conjunto, el valor de los elementos que se enviaron a América ascendió a la cantidad de 30.234 pesetas, que si tenemos en cuenta que lo contabilizado es desde noviembre de 1927 a marzo de 1928, supone una cantidad, para entonces, nada despreciable.

Hay que considerar también que los exportadores sevillanos que constan en los documentos de la Aduana de Sevilla durante este tiempo eran solamente doce $^{3}$, aunque de estos hay firmas que hacen un único envío, y modesto, lo que nos hace suponer que en realidad no eran comerciantes, sino particulares que por algún medio habían vendido objetos a casas privadas o incluso a compañías en América.

A este caso corresponde un envío que la Señora Viuda de Barrón hace a la Compañía Hudson Forwarding, en New York, por valor de ciento cuarenta y cinco pesetas, consistente en seis piezas mobiliares de escasa importancia $y$, aunque de estilo español, modernas.

Otro caso parecido, aunque se trataba de un comerciante acreditado, es el de Don Pedro Trigo, establecido en la calle Feria n. ${ }^{\circ}$ 138, que también a New York, y a Mr. George E. Fahys, manda una partida de cuatro piezas de hierro, unas de

3. Para comprobar cualquier dato acerca de Anticuarios, Exportaciones, etc., consultar el índice final, en el que, por orden alfabético y cronológico, aparecen reseñadas cada una de las casas exportadoras e importadoras, con el volumen de sus transacciones y el detalle de las piezas. 
fundición y otras de forja, consistentes en dos balcones, una reja y un brocal de pozo, todo ello por seiscientas pesetas, haciendo constar que el brocal de pozo supuso la mitad del precio del embarque completo.

Por su parte, Doña Carmen Bueno, que no tiene establecimiento comercial conocido, exporta a Baltimore (Maryland) una serie de piezas, de vidrio y porcelana, que se valoran en trescientas cuarenta y ocho pesetas.

Se trata de dos dulceras de vidrio blanco tallado, con sus tapaderas, en forma de sopera; ocho copas de vidrio verde, también tallado, de un modelo de pie bajo, que se hicieron muy populares en el S. XIX, y dos escribanías de porcelana inglesa, compuestas por figuras tipo "bibelot", que también aparentan ser decimonónicas, al menos por el vestuario de los personajes que las adornan.

Otro envío de poca monta es el que hace Don Manuel Montero con destino a Los Angeles, en California, a cargo de Mr. J. Rappe Mijers, por valor de quinientas cincuenta y ocho pesetas, consistente en ocho piezas de hierro, unas de fundición y otras de forja.

Una firma bastante conocida en el mundo de las antiguiedadẹs actualmente es la de Ortega, no obstante, en esta época aparece Don Manuel Ortega con un solo envío por el precio de setecientas pesetas, que constó de veintisiete objetos de hierro y metal que fueron a Cleveland (Ohio) a la consigna de la Compañía The Rose Iron Work.

A la vista de los documentos en los que nos basamos, las dos casas más fuertes en el momento eran la de Don Abelardo Linares y la de Don Manuel Adarve, a los que además del negocio también unían lazos familiares, formando entre ambos una auténtica sociedad, si bien en estos tiempos que tratamos sus firmas eran independientes.

Estos comerciantes no solamente tenían establecimientos en Sevilla, sino que también tenían sucursales en otros lugares de España, así como en Estados Unidos.

Linares, en Sevilla, estaba establecido en la Plaza del Triunfo n.ำ 1, y también tenía tiendas en Granada, Madrid y Toledo, y además en New York, a nombre de Doña Josefa Linares, a la que fueron destinadas algunas partidas procedentes de distintas casas españolas, aunque no de la de Sevilla ${ }^{4}$.

Este anticuario exportó multitud de piezas, en total cincuenta y nueve, pero entre ellas no se encuentran las más cotizadas.

El precio más alto de cuanto envió es de setecientas pesetas que se pagaron por un contador del S. XVII, decorado con labor de taracea, que figuraba jarrones y verduras.

4. Don Manuel Adarve, desde su casa de Granada, envió a Doña Josefa Linares, en New York, por medio de la Aduana de Sevilla y por mediación de la Compañía Bakumar, un lote de 28 piezas valoradas en un total de 3.360 pesetas el 10 de noviembre de 1927. 
En total, los embarques de antigüedades de esta firma supusieron nueve mil novecientas veinticinco pesetas, siendo solamente tres los que realizó, dos a New York, a la firma Pitt and Scott, que supusieron la mayoría de las piezas, puesto que el tercero, con destino a Pasadena (California), a Mrs. Lena S. Ranquin, sólo consistió en un sillón con respaldo y asiento de cuero labrado que se valoró en cuatrocientas pesetas.

Don Manuel Adarve, desde su casa en Sevilla, mandó a New York piezas que importaron en conjunto nueve mil setenta pesetas, entre las que se encontraba la Inmaculada ya referida (vid. fig. 3 ).

No obstante el prestigio de estos anticuarios, no fueron ellos los que exportaron las piezas mejores, al menos por el precio en que se las valoró, aunque hay que tener en cuenta la fluctuación del mercado.

Algunos comerciantes poco conocidos actualmente exportaron las obras más preciadas. Una de ellas fue un brocal de pozo de hierro que Don Francisco Piñanes envió a Pasadena, en California, y que se valoró en mil setecientas cincuenta pesetas.

Este brocal de pozo, posiblemente obra de los finales del S. XVI, según podemos ver en la imagen (fig. 4), se completa con el arco de la garrucha, que es evidentemente posterior.

Otra de las obras más cotizadas fue un mueble bargueño que Don Juan Muñoz López envió a Mr. M. M. Noon en New York. El dicho bargueño, posiblemente de los comienzos del S. XVI, presenta una decoración arquitectónica tardorenacentista, muy cuidada, y por lo que se puede apreciar a través de los elementos gráficos en los que nos basamos, es un mueble de muy buena calidad y madera noble.

La mesa es de puente, con tres soportes, en los que se combinan los balaustres con la columna torsa, así como la chambrana presenta una talla muy simple, lo que nos hace pensar en una composición un tanto ecléctica (fig. 5). A pesar de las dificultades de catalogación, el precio en que se valoró, mil quinientas pesetas, no parece excesivo.

Otros comerciantes exportaron el producto de almonedas y grandes cantidades de objetos de poco valor, pero que como elementos decorativos parece ser que tenían una buena aceptación en el mercado americano.

Este, por ejemplo, es el caso de Don José Pomés, que independientemente de la imagen de la Virgen que ya citamos con anterioridad (vid fig. 2), hace un envío a Mr. Gustave Kellner, en New York, de veintiún tazones de loza, de distintos tamaños y procedencias, todos por ciento setenta y cinco pesetas, además de un curiosísimo mortero tallado, con diseño del S. XVII (fig. 6), decorado con tarjas, jarrones y guirnaldas, que se valoró en la no despreciable cantidad, teniendo en cuenta la época, de cuatrocientas diez pesetas. 
Don José Pomés, que estaba establecido en la calle Méndez Núñez, aunque el número de exportaciones que hizo en las fechas de las que nos ocupamos no fue muy cuantioso, debió ser un anticuario de bastante prestigio, puesto que los objetos con los que comercia son en su mayoría de una calidad muy alta.

Don Celestino Dupont, que tenía su casa en la calle Albareda n. $\stackrel{0}{34}$, entra en la misma línea que el Sr. Pomés. Evidentemente en sus envíos iban piezas de poca monta, pero junto a ellas mandó a América, concretamente a Mr. Laurence Habart Shearman, en New York, uno de los objetos más preciados de cuantos salieron por nuestra Aduana, y fue un bargueño, valorado en mil ochocientas pesetas (vid fig. 1) que pasó el Atlántico acompañado de otras tres piezas consistentes en dos mesitas de poca importancia y un sencillo velón de cobre.

Este bargueño, obra posiblemente del S. XVII, tiene guarniciones de hierro muy bien labradas, así como también presenta una buena calidad el mueble de soporte, decorado con casetones y rosetas. Constituye una de las piezas de mobiliario más importante de cuantas se exportaron.

Dos envíos fueron los que hizo Don Eugenio Ribette, ambos destinados a la ciudad de New York. Uno a Mr. Bernard Epstein, cuya pieza más importante fue una cómoda-escritorio, de estilo neoclásico, con adornos de bronce tanto en los tiradores como en las bocallaves, que se valoró en setecientas pesetas.

El otro, que fue a la consigna de Doña Isabel Ross, estaba formado por varios objetos, valorados en su totalidad en dos mil treinta y cinco pesetas, entre los que se encontraban algunos elementos curiosos, como una talla pequeña de una Virgen con Niño, posiblemente del S. XVIII; un libro de Ejecutoria de Nobleza del reinado de Carlos II, en el que vemos una preciosa miniatura representando a la Inmaculada y el escudo de los Austria y dos dalmáticas y una casulla, también dieciochescas, bordadas en sedas de colores.

Por regla general, en casi todos los embarques encontramos piezas interesantes, independientemente de su valor económico. Citaremos solamente algunos casos, puesto que la relación completa de lo exportado la incluimos al final de este trabajo.

Por ejemplo, Don Manuel Adarve, dentro de una partida de veinte piezas que manda a Mr. Albert Stratton, en New York, incluye una pequeña talla de Santo valorada en doscientas pesetas, de factura muy aceptable. Posiblemente se trata de un San Isidro, y parece de escuela sevillana del S. XVII. También en el mismo lote va un banco-arcón de madera tallada, en cuyo respaldo podemos ver representado el escudo franciscano. Este mueble está ricamente decorado con tallas de diferentes motivos, y es un típico banco de Sacristía (fig. 7).

Otra pieza curiosa es un busto de "demonio" tallado en madera, tardogótico, que costó trescientas pesetas y que fue al mismo destino que las dos obras anteriores.

Abelardo Linares a Pitt and Scott, también en New York, envía piezas impor- 
tantes, sobre todo en lo que a muebles se refiere, entre ellos un arca tardogótica con el escudo de los Reyes Católicos de una calidad aceptable; una silla de tijeras con asiento y respaldo de cuero labrado, y varios arcones con decoración barroca, entre las cuarenta y nueve piezas que supone su embarque.

En fin, el total de piezas exportadas en el corto espacio que nos ocupa, apenas seis meses, alcanza la suma de doscientas noventa y una, y como hemos comentado, eran de calidades y valores muy diferentes.

Contabilizándolas por bloques y tipos, el mayor número de objetos los compusieron los hierros, aunque entre ellos no había ninguna homogeneidad, yendo desde un valioso brocal de pozo (vid. fig. 6) hasta una serie de hojas de hierro sin labrar. Pasando por rejas, espeteras y otras obras de forja y de fundición que en total supusieron noventa y cinco.

Le seguía en cantidad el mueble, con sesenta y tres piezas, muchas de ellas de un alto valor artístico y que, como hemos visto anteriormente, alcanzaron un precio considerable en el mercado. Son los bargueños, sobre todo, los elementos más cotizados, aunque junto a ellos se enviaron, como siempre, objetos de escasísimo interés.

Después nos encontramos con las cerámicas, que también fueron numerosas, cincuenta y dos en total, con abundancia de las de Triana y Talavera.

Los tejidos, que fueron veintiuno, en su mayoría eran ternos eclesiásticos, aunque también se contemplan bordados populares y textiles alpujarreños.

Muy por debajo de estas cifras se encuentran una serie de objetos de vidrio (catorce) entre los que destacan en número las copas de pie bajo. Los de hoja de lata, sobre todo faroles (trece), el mismo número lo componen los cobres, por lo general velones y calderillos, salvo un brasero.

La escultura, con ser escasa (nueve figuras en total), cuenta con algunas tallas interesantes. Y por último, hay una serie de objetos varios que componen un bloque de catorce, que son piezas sueltas, entre las que se cuenta con un abanico, una Ejecutoria de nobleza y otras a las que ya hicimos alusión (fig. 8).

Desgraciadamente, y a pesar de la exactitud de las relaciones aduaneras que hemos consultado, en ellas no se especifican las características artísticas de las obras, por lo que necesariamente hemos tenido que recurrir a comparaciones con elementos ya bien catalogados en Museos o en colecciones particulares, pero, como es obvio, el análisis de cualquier objeto no puede ser medianamente exacto sin tenerlo materialmente presente.

Aunque el material gráfico con el que hemos trabajado es amplio, su calidad es muy irregular, por eso, para no magnificar ni minimizar las exportaciones reseñadas, hacemos de algunas, las más curiosas, o de las que adquirieron una valoración mayor, un somero comentario, sin pretender nunca que sea una catalogación rigurosa, porque sería imposible. 


\section{RELACIÓN DETALLADA DEL COMERCIO DE OBJETOS DE ARTE PROCEDENTES DE ANTICUARIOS SEVILLANOS CON AMÉRICA (1927-1928)}

\begin{tabular}{|c|c|c|c|c|c|}
\hline Exportador & Fecha & Importador & Destino & Objeto & $\begin{array}{l}\text { Precio } \\
\text { Ptas. }\end{array}$ \\
\hline ADARVE, Manuel & $7-1-1928$ & Lena S. Rankin & Pasadena (Calf.) & $\begin{array}{l}3 \text { Tapetes bordados } \\
2 \text { Candeleros hierro forja } \\
1 \text { Mesa pequeña } \\
1 \text { Escritorio } \\
1 \text { Orza de Fajalauza } \\
2 \text { Calderillas de cobre } \\
1 \text { Capuchina (candil) de cobre } \\
6 \text { Sillas con asiento y respaldo } \\
\text { de cuero labrado } \\
2 \text { Sillones con respaldo y asiento } \\
\text { de cuero labrado }\end{array}$ & $\begin{array}{r}30 \\
115 \\
90 \\
365 \\
15 \\
4 \\
3 \\
900 \\
400\end{array}$ \\
\hline ADAR VE, Manuel & $20-3-1928$ & Gustave Kellner & New York & $\begin{array}{l}1 \text { Escritorio estilo Renacimiento } \\
1 \text { Alfombra de lana con flecos } \\
2 \text { Cojines modernos bordados } \\
\text { en lana } \\
2 \text { Sillones estilo Renacimiento } \\
1 \text { Banco de madera } \\
1 \text { Mesa }\end{array}$ & $\begin{array}{r}770 \\
400 \\
\\
30 \\
725 \\
700 \\
250\end{array}$ \\
\hline ADARVE, Manuel & $20-3-1928$ & Helen Carver & Bakerfield (Calf.) & 1 Brasero de cobre & 20 \\
\hline ADARVE, Manuel & $28-3-1928$ & Albert E. Stratton & New York & $\begin{array}{l}1 \text { Talla de la Inmaculada } \\
\text { S. XVII (fig. 3) } \\
1 \text { Espetera completa de hierro } \\
1 \text { Jarro verde de cerámica popular } \\
1 \text { Almirez de cobre } \\
1 \text { Brasero de cobre con tarima } \\
\text { I Santo tallado en madera } \\
\text { S. XVII (posiblemente S. Isidro) } \\
2 \text { Angeles de talla, pequeños } \\
2 \text { "Morillos" de hierro } \\
1 \text { Busto de Demonio tallado } \\
\text { en madera, posible del S. XVI } \\
2 \text { Tipos populares de "naranjeros" } \\
1 \text { Mesa bandeja plegable } \\
1 \text { Mesa moderna, estilo Español } \\
2 \text { Platos de Talavera con } \\
\text { decoración tipo Renacimiento } \\
1 \text { Banco de madera, } \\
\text { S. XVIII (fig. 7) } \\
1 \text { Marco dorado con decoración } \\
1 \text { Jarro dorado cerámica Talavera } \\
1 \text { Plato dorado cerámica Talavera }\end{array}$ & $\begin{array}{r}1.620 \\
40 \\
5 \\
5 \\
300 \\
\\
200 \\
200 \\
100 \\
\\
300 \\
6 \\
60 \\
120 \\
200 \\
\\
350 \\
125 \\
50 \\
50\end{array}$ \\
\hline BARRON, Vida. de & $18-1-1928$ & $\begin{array}{l}\text { Hudson } \\
\text { Forwarding Co. }\end{array}$ & New York & $\begin{array}{l}1 \text { Banco de madera moderno } \\
1 \text { Marco moldura sencilla, moderno } \\
2 \text { Velones de cobre } \\
2 \text { Candeleros de hierro }\end{array}$ & $\begin{array}{r}75 \\
5 \\
15 \\
50\end{array}$ \\
\hline
\end{tabular}




\begin{tabular}{llll} 
& & Precio \\
Exportador Fecha & Importador & Destino & Plas. \\
\hline
\end{tabular}

BUENO, Carmen 27-2-1928 Oliver Carrl Zell. Jr. Baltimore (Mrld.) 2 Dulceras vidrio tallado y

2 Escribanías de porcelana inglesa 265

6 Vasos de vidrio verde

DUPONT, Celestino 27-2-1928 Robert E. Strarhom San Francisco (Calf.)

1 Cafetera China con pie

1 Abanico con país pintado

DUPONT, Celestino 27-11-1927 Frank Mattiesson

Beverly Hills.

Los Angeles 2 Butacas estilo Renacimiento y

1 Mesa Renacimiento

DUPONT, Celestino 22-11-1927 Laurence Habart Shearman

New York

1 Mesita tallada

250

1 Mesita tallada

300

1 Velón de cobre

1 Mueble bargueño mudéjar

S. XVI (fig. 1)

FERNANDEZ, Juan 22-11-1927 George E. Fahys New York

LINARES, Abelardo 1-12-1927 Pitt and Scott New York

2 Cancelas completas

400

4 Lámparas de hierro

1 Repostero terciopelo bordado $\quad 450$

2 Comucopias

1 Jarra verde cerámica popular con pie de hierro

2 Platos cerámica de Triana

2 Jarras cerámica de Triana

1 Cama Española con barrotes torneados

1 Mesa tipo San Antonio 275

1 Mesa mediana 90

1 Mesa mediana 75

1 Mesa pequeña 35

2 Asas de bronce (regalo)

1 Mueble pequeño con cajones

1 Contador con decoración

de taracea formando jarrones

\begin{tabular}{|c|c|c|c|c|c|}
\hline LINARES, Abelardo & $7-1-1928$ & Lena S. Ranquin & Pasadena (Calf.) & $\begin{array}{l}1 \text { Sillón con respaldo y asiento } \\
\text { de cuero labrado }\end{array}$ & 400 \\
\hline LINARES, Abelardo & $27-3-1928$ & Pitt and Scott & New York & $\begin{array}{l}1 \text { Mesa estilo Renacimiento y } \\
1 \text { Sillón estilo Renacimiento } \\
1 \text { Armario tallado S. XVIII } \\
2 \text { Sillones } \\
2 \text { Candeleros de hierro } \\
1 \text { Arca tallada } \\
1 \text { Silla con asiento de cuero } \\
\text { labrado y escudo en el respaldo } \\
1 \text { Sillón, } \\
2 \text { Candeleros de hierro, } \\
1 \text { Mesa y } \\
2 \text { Tiras de terciopelo bordado }\end{array}$ & $\begin{array}{l}550 \\
600 \\
300 \\
200 \\
400 \\
175\end{array}$ \\
\hline
\end{tabular}




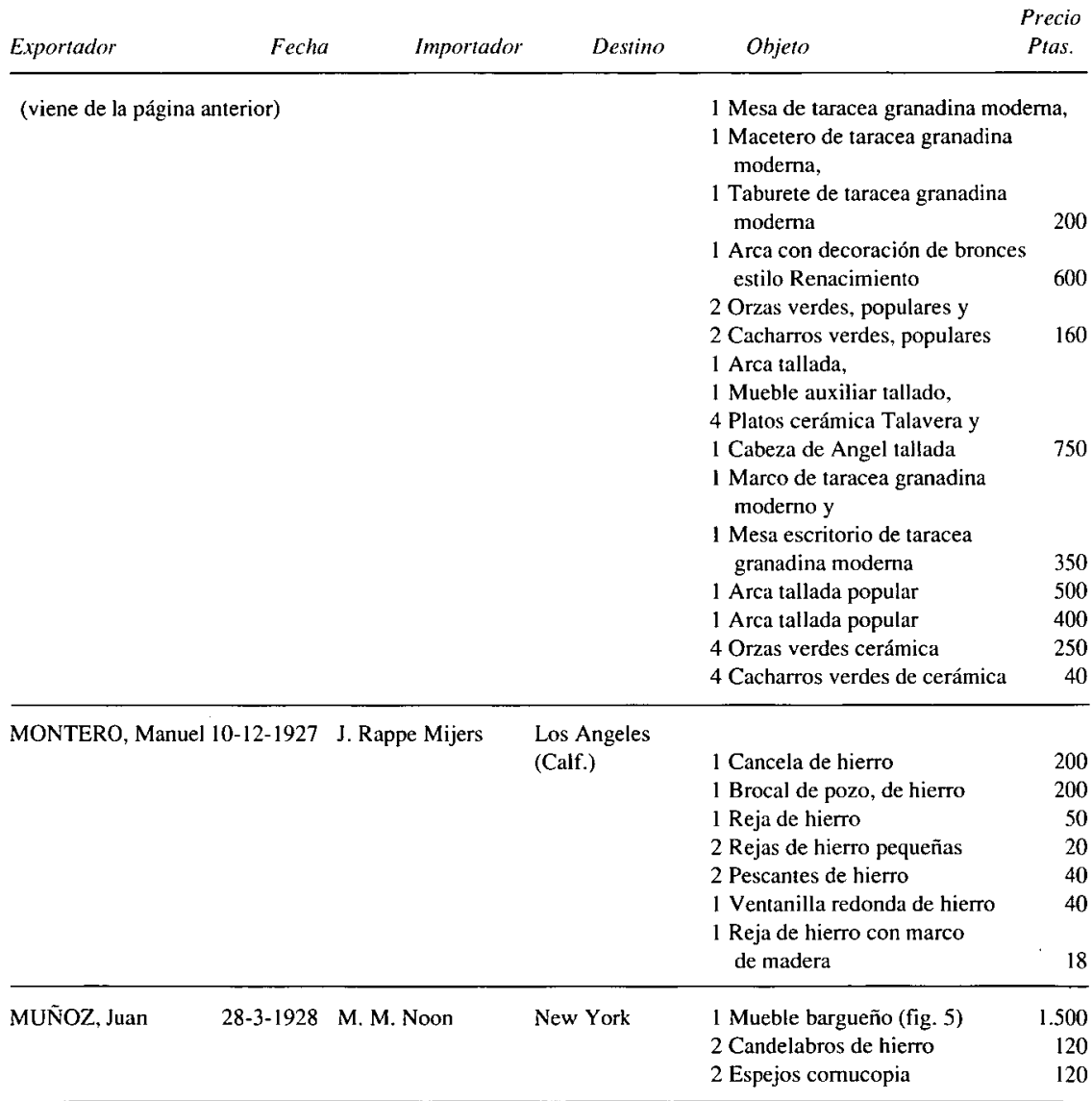

\begin{tabular}{|c|c|c|c|c|c|}
\hline ORTEGA, Manuel & $30-3-1928$ & $\begin{array}{l}\text { The Rose Iron } \\
\text { Work }\end{array}$ & Clevelan (Ohio) & $\begin{array}{l}6 \text { Faroles de hoja de lata } \\
\text { 1 Estrella de latón y } \\
1 \text { Lámpara de latón } \\
5 \text { Espeteras de hierro } \\
1 \text { Cisnero de hierro } \\
1 \text { Olla de cobre con pie de hierro } \\
2 \text { Veletas de hierro con figuras } \\
2 \text { Partes altas de espetera } \\
6 \text { Veleros de pared de hierro }\end{array}$ & $\begin{array}{r}150 \\
120 \\
100 \\
100 \\
80 \\
50 \\
40 \\
60\end{array}$ \\
\hline PIÑANES, Francisc & $12-12-1927$ & Lena S. Rankin & Pasadena (Calf.) & $\begin{array}{l}1 \text { Brocal de pozo con su pretil } \\
\text { de hierro. S. XVI c. (fig. 4) } \\
18 \text { Hojas de hierro sin labrar }\end{array}$ & $\begin{array}{r}1.750 \\
36\end{array}$ \\
\hline POMES, José & $1-12-1927$ & Henry Rothman & New York & 1 Mesa moderna de madera & 40 \\
\hline
\end{tabular}




\begin{tabular}{|c|c|c|c|c|c|}
\hline Exportador & Fecha & Importador & Destino & Objeto & $\begin{array}{l}\text { Precio } \\
\text { Ptas. }\end{array}$ \\
\hline POMES, José & $17-3-1928$ & Gregorio Centurión & Buenos Aires & $\begin{array}{l}1 \text { Talla en madera de Virgen } \\
\text { con Niño posiblemente fines } \\
\text { S. XVI (fig. 2) } \\
8 \text { Hierros de forja sin importancia }\end{array}$ & $\begin{array}{r}400 \\
40\end{array}$ \\
\hline POMES, José & $17-3-1928$ & Gustave Kellner & New York & $\begin{array}{l}1 \text { Botijo verde popular } \\
1 \text { Tinaja árabe con pie de hierro } \\
1 \text { Mortero de madera tallado } \\
\text { S. XVII (fig. 6) } \\
1 \text { Frontal de Altar. S. XVIII y } \\
2 \text { Casullas } \\
2 \text { Pañitos bordados y } \\
1 \text { Repostero } \\
1 \text { Arca de madera tallada. S. XIX } \\
1 \text { Arca de madera con talla popular } \\
21 \text { Tazones de loza de Triana } \\
4 \text { Espeteras de hierro } \\
2 \text { Sillones de madera modemos }\end{array}$ & $\begin{array}{r}50 \\
300 \\
\\
410 \\
\\
200 \\
\\
125 \\
200 \\
200 \\
175 \\
75 \\
200\end{array}$ \\
\hline RIBETTE, Eugenio & $10-12-1927$ & Bernard Epstein & New York & $\begin{array}{l}1 \text { Cómoda-escritorio estilo Imperio } \\
\text { con guarniciones de bronce }\end{array}$ & 750 \\
\hline RIBETTE, Eugenio & $10-12-1927$ & Isabel Ross & New York & $\begin{array}{l}1 \text { Virgen con Niño de talla } \\
\text { en madera, posiblemente } \\
\text { S. XVIII finales } \\
1 \text { Libro de Ejecutoria de Nobleza } \\
\text { del reinado de Carlos II } \\
1 \text { Crucifijo de marfil S. XVIII } \\
1 \text { Tintero de cerámica de Triana, } \\
\text { de tres cazoletas } \\
1 \text { Frontal de Altar grana y } \\
2 \text { Trozos de paño "gótico"? } \\
2 \text { Dalmáticas S. XVIII y } \\
1 \text { casulla S. XVIII }\end{array}$ & $\begin{array}{r}100 \\
250 \\
175 \\
10 \\
400 \\
1.100\end{array}$ \\
\hline
\end{tabular}




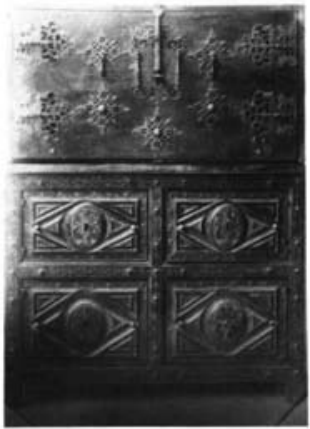

Figura 1

Mueble bargueño, inspirado en diseño mudéjar S. XVII. Exportado por D. Celestino Dupont a la Consigna de Laurence Habart Shearman, en New York. (22-11-1927). Valor: 1.850 pesetas.

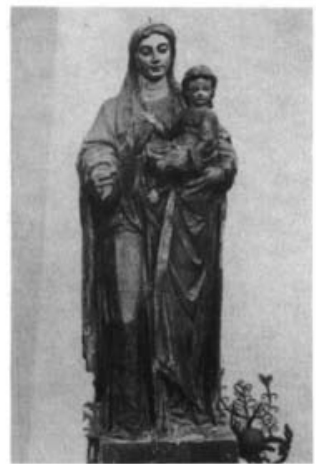

Figura 2

Virgen con Niño, Posiblemente del S. XV. finales. Exportada por D. José Pomes a D. Gregorio Centurión, en Buenos Aires. (17-3-1928). Valor: 400 pesetas. 


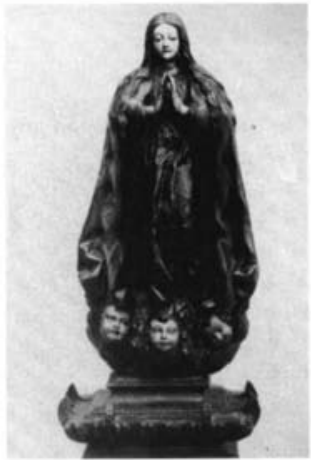

Figura 3

Inmaculada Concepción. Escuela Granadina. S. XVII. Exportada por D. Manuel Adarve a Albert E. Stratton en New York. (28-3-1928), Valor: 1.620 pesetas.

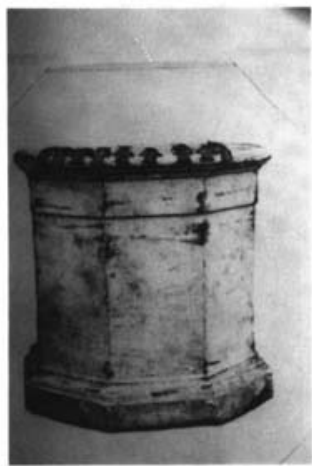

Figura 4

Brocal de pozo. S. XVII. Exportado por D. Francisco Piñanes a Lena S. Rankin, en Pasadena (Califormia), (12-12-1927). Valor: 1.750 pesetas. 


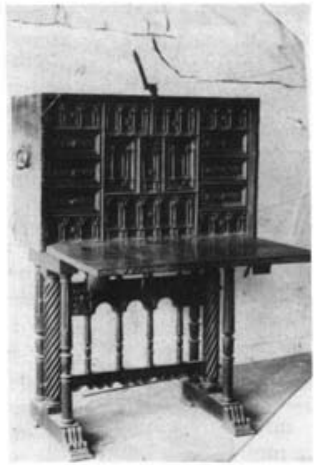

Figura 5

Mueble bargueño, con pie de puente. Finales del S. XVI. Exportado por D. Juan Muñoz a M. M. Noon. en New York. (28-3-1928). Valor. 1.500 pesetas.

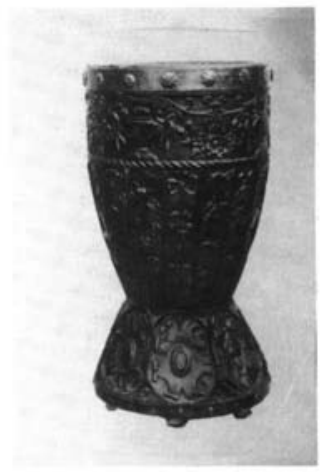

Figura 6

Moricio de madera, tallado. Comicnzos de! S. XVI. Exportado por D. José Pomes a Gustave Kellner, en New York. (17-3-1928), Valor: 410 pesetas. 


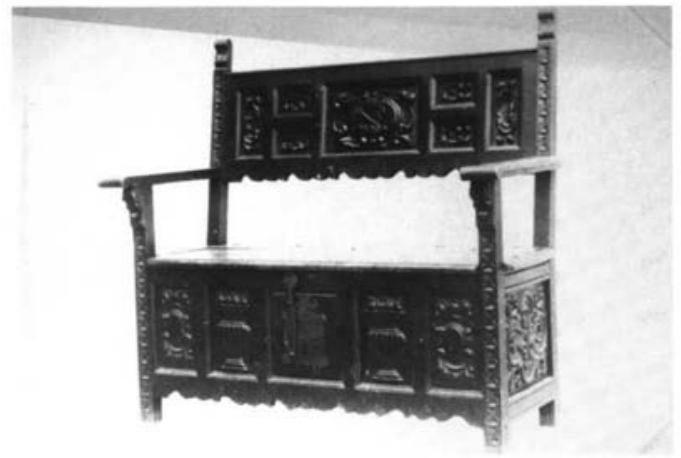

Figura 7

Banco de Sacristía, con areón en el asiento. Madera tallada y guarnecida con hierro. Tiene tallado el escudo franciscano en el respaldo. S. XVIII. Exportado por D. Manuel Adarve a Alben E. Stratton. en New York. (28-3-1928). Valor: 350 pesetas.

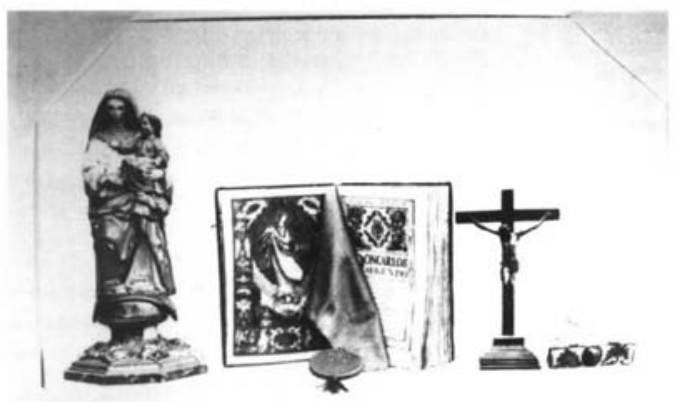

Figura 8

Varios objetos enviados por D. Eugenio Ribette a D.' Isabel Ross, en New York, (10-12-1927). El conjunto del envio, aún teniendo en cuenta la buena calidad de algunas de las piezas que lo componen, fue valorado en su totalidad en 635 pesetas. 